\title{
ET interactive?
}

No. Not English Today in cyberspace - or at least not yet. Rather, it could be a move towards more discussion and fuller reader involvement: something that email can make easier for everybody, including those who don't yet or won't ever use it directly.

As regular readers know, the POST \& MAIL section has always been highly popular, yet in the last two years or so it has virtually dried up. More people have been sending in full-length articles than shorter comments and many others simply haven't had the time to write. Yet at the same time they have expressed their regret that other people haven't been continuing with 2 letters. And as editor, I have particularly regretted this development. My own share of the blame is that often I haven't in recent years had the time to answer conventional letters promptly (or at all) or importantly - to coax a letter to the editor out of someone I know has something to say.

But that could change. In this issue, POST \& MAIL is back in full form, but adapted hopefully to POST \& (E)MAIL (p. 62). There are eight letters of varying lengths in this issue, one of which has a response from me while another has responses from me and from a recent contributor, Ross Smith. Such an approach makes possible a regular reader-contributor-editor exchange not possible when the basic means of contact worldwide was stamp-andenvelope. That medium is still of course vital for many reasons (including delivering ET every quarter), but most contributors now have email and I can therefore not only involve them more (and more quickly) in editing but also ask them for a reply to a reader's comment or query, get it quickly, and drop it neatly into its slot for the next issue.

Such an approach can make ET's on-going debate easier and more satisfying for everybody. Readers should also feel free to use email and fax for editorial matters (to me) and administrative matters (to Cambridge University Press): addresses in the column on the right. These days, I can guarantee a surer response to email or fax than conventional post, although I also hope to speed that up too.

Tom McArthur

The editorial policy of English Today is to provide a focus or forum for all sorts of news and opinion from around the world. The points of view of individual writers are as a consequence their own, and do not reflect the opinion of the editorial board. In addition, wherever feasible, ET generally leaves unchanged the orthography (normally British or American) and the usage of individual contributors, although the editorial style of the journal itself is that of Cambridge University Press. 